\title{
An observational study to evaluate the maternal and neonatal outcome of forceps delivery in a tertiary care government hospital of a cosmopolitan city of India
}

\author{
Akanksha Lamba*, Ramanjeet Kaur, Zulaihuma Muzafar
}

Department of Obstetrics \& Gynaecology, Kasturba Hospital, New Delhi, India

Received: 27 December 2015

Accepted: 08 January 2016

\author{
*Correspondence: \\ Dr. Akanksha Lamba, \\ E-mail: dr.akanksha2709@gmail.com
}

Copyright: (C) the author(s), publisher and licensee Medip Academy. This is an open-access article distributed under the terms of the Creative Commons Attribution Non-Commercial License, which permits unrestricted non-commercial use, distribution, and reproduction in any medium, provided the original work is properly cited.

\begin{abstract}
Background: Operative vaginal delivery using obstetric forceps is a practice that dates back several centuries. Modern obstetrics practice has witnessed an increase in the caesarean section rates. The goal of forceps delivery is to mimic spontaneous vaginal birth, thereby expediting delivery with a minimum of maternal or neonatal morbidity. The main objective of study was to evaluate the maternal and neonatal outcome of forceps assisted deliveries in a tertiary care hospital over a period of one year.

Methods: This retrospective observational study was done in obstetrics and gynecology department of Kasturba Hospital, Delhi from November 2014 to October 2015. Seventy cases of forceps delivery were studied for maternal outcome such as injuries, postpartum hemorrhage, need of blood transfusion and fetal outcome such as birth weight, Apgar scores at birth, neonatal intensive care unit admissions, injury, still births and neonatal mortality.

Results: $68.5 \%$ of patients requiring forceps application were primigravida. The most common indication was fetal distress $(54.2 \%)$ followed by maternal exhaustion. The most common maternal complication was extension of episiotomy (10), 1 case of uterine rupture which was in a previous lower segment caesarean section case, 2 complete perineal tears, 3 cases of vaginal and cervical lacerations. Postpartum hemorrhage requiring blood transfusion occurred in 4 cases. A total of 19 babies had poor Apgar scores and 9 of them needed NICU admission. There were 3 cases of still births and 2 of early neonatal deaths.

Conclusions: The second stage interventions are associated with increased maternal and neonatal morbidity. Judicial use forceps under close supervision and with proper expertise can reduce the caesarean section rates.
\end{abstract}

Keywords: Forceps, Morbidity, Maternal outcome, Neonatal outcome

\section{INTRODUCTION}

Assisted vaginal delivery is a key element of essential obstetric care and obstetrical forceps have been an integral part of obstetrician's equipment's. The obstetric forceps has its history from the time of Chamberlain family in the seventh century and it has undergone numerous modifications to evolve into its present form. Forceps delivery whilst carrying its own attendant risk can often facilitate child birth in the second stage of labour, thus avoiding caesarean section. ${ }^{1}$ The increased risk of neonatal morbidity in relation to forceps delivery is long established although with careful practice overall rates of morbidity are low. ${ }^{2}$ Although several authors have reported the relative safety of forceps delivery many obstetricians have abandoned the use of this intervention. ${ }^{3}$ There is a concern about the dramatically rising rates of caesarean delivery worldwide as unnecessary caesarean sections are associated with increased maternal and perinatal morbidity. ${ }^{4,5}$ Thus in the present day reintroduction of the art of using forceps will 
definitely help in reducing the caesarean section rates and its comorbidities.

This study was done to evaluate the maternal and neonatal outcome of forceps assisted deliveries in a tertiary care hospital over a period of one year.

\section{METHODS}

This is a retrospective observational study which was carried out in the department of Obstetrics and Gynecology of Kasturba Hospital, Delhi, India over a period of one year from November 2014 to October 2015. All cases of forceps deliveries over this period were included, a total of 70 , all of which were singleton pregnancies with fetus in cephalic presentation. The forceps used was Wrigley's outlet forceps. Right mediolateral episiotomy and perineal infiltration (lignocaine) was done as a routine. Cases were scrutinized for demographic data, gestational age and indication for instrumental delivery. The various indications for forceps delivery were fetal distress, failure of descent of head, to cut short second stage of labor, poor maternal efforts. Maternal outcomes of interest were genital tract injuries (uterine rupture, vaginal wall tear, cervical tear, vulvo-vaginal hematoma, 3 and 4 degree perineal tears and paraurethral tears), extended episiotomy, postpartum hemorrhage, need of blood transfusion and length of hospital stay. Neonatal outcomes of interest were birth weight, apgar scores, scalp and facial injuries, NICU admission, stillbirth, neonatal mortality.

\section{RESULTS}

A total of 70 cases were studied. Sociodemographic profile of the cases is shown in Table 1. The mean age of the patients was 26.2 years. 48 patients were primigravida and 22 were multigravida. $14.2 \%$ of patients requiring this intervention had crossed the gestational age of 40 weeks.

Table 1: Sociodemographic profile.

\begin{tabular}{|llcc|}
\hline Characteristics & Groups & Number & Percentage \\
\hline \multirow{3}{*}{ Age (years) } & $<20$ & 17 & 24.2 \\
\cline { 2 - 4 } & $20-30$ & 28 & 40 \\
\cline { 2 - 4 } & $30-40$ & 21 & 30 \\
\cline { 2 - 4 } & $>40$ & 04 & 5.7 \\
\hline \multirow{2}{*}{ Parity } & Primi & 48 & 68.5 \\
\cline { 2 - 4 } & Multi & 22 & 31.4 \\
\hline \multirow{2}{*}{$\begin{array}{l}\text { Gestational age } \\
\text { (weeks) }\end{array}$} & $37-40$ & 58 & 2.8 \\
\cline { 2 - 4 } & $>40$ & 10 & 82.8 \\
\hline
\end{tabular}

Table 2 shows the indication of forceps application. The figures reveal that the most common indication for application of forceps was non-reassuring fetal heart rate
(54.2\%) followed by maternal exhaustion, failure of descent of head and to cut short second stage of labour.

Table 2: Indications of forceps application.

\begin{tabular}{|lcc|}
\hline $\begin{array}{l}\text { Indication } \\
\text { Non reassuring } \\
\text { fetal heart rate }\end{array}$ & 38 & 54.2 \\
\hline $\begin{array}{l}\text { Maternal } \\
\text { exhaustion }\end{array}$ & 13 & 18.5 \\
\hline $\begin{array}{l}\text { Failure of descent } \\
\text { of head }\end{array}$ & 10 & 14.2 \\
\hline $\begin{array}{l}\text { Cut short second } \\
\text { stage of labour }\end{array}$ & 09 & 12.8 \\
\hline $\begin{array}{l}\text { 1.Previous LSCS } \\
\text { 2.Eclampsia }\end{array}$ & 04 & 5.7 \\
3.Severe Anemia & 03 & 4.2 \\
\hline
\end{tabular}

Table 3 summarizes the maternal morbidity due to forceps application. Extension of episiotomy (14.2\%) was the most common complication noted. A total of 9 cases of maternal injuries were noted with 1 case of uterine rupture, 2 cases of complete perineal tear, 3 cases of vaginal and cervical lacerations and 1 case of paraurethral tear. Vulvovaginal hematoma was seen in 2 cases which were drained immediately after diagnosis. Furthermore, postpartum hemorrhage occurred in 6 cases, 4 being atonic and 2 traumatic. Blood transfusion was required in 4 cases of pph. Uterine rupture was reported in a second gravida with previous lower segment cesarean section (LSCS) where outlet forceps was applied for fetal distress and a $2.8 \mathrm{~kg}$ baby delivered. On postnatal day one the patient had positive signs of peritonitis, haemoperitoneum was reported on ultrasound, laparotomy was done and scar rupture was diagnosed. Subtotal hysterectomy was done and the patient was transfused 3 units of whole blood. Her post-operative stay was uneventful. Hospital stay was lengthened in 5 patients as they were discharged after 48 hours of delivery. The patients with complete perineal tear were discharged after passing stools and when there wound looked healthy.

The baby weights are shown in Table 4. Mean birth weight in our study was $2.84 \mathrm{~kg}$. Forceps application was generally seen in babies of high birth weight.

Regarding the neonatal morbidity (Table 5), 19 babies had Apgar score of less than 6 at 1 minute and required resuscitation. 3 still births were reported and 9 required NICU admission out of which 3 were put on ventilator support. 2 babies expired on the second day and rests were discharged in satisfactory condition. Instrumental marks and bruises were reported in $10 \%$ cases, subconjunctival hemorrhage in $1.4 \%$ and facial palsy in $2.8 \%$. Meconium stained liquor was observed in $36 \%$. 
Table 3: Maternal morbidity.

\begin{tabular}{|lcc|}
\hline Morbidity conditions & Number & Percentage \\
\hline Episiotomy extension & 10 & 14.2 \\
\hline Maternal injuries & 09 & 12.8 \\
\hline $\begin{array}{l}\text { (a) Vaginal and cervical } \\
\text { lacerations }\end{array}$ & 03 & 4.2 \\
\hline $\begin{array}{l}\text { (b)Third and fourth degree } \\
\text { perineal tear }\end{array}$ & 02 & 2.8 \\
\hline $\begin{array}{l}\text { (c) Paraurethral tear } \\
\text { (d)Vulvo vaginal hematoma }\end{array}$ & 01 & 1.4 \\
\hline (e)Uterine rupture & 02 & 2.8 \\
\hline $\begin{array}{l}\text { Postpartum hemorrhage } \\
\text { requiring blood transfusion }\end{array}$ & 04 & 1.4 \\
\hline $\begin{array}{l}\text { Increased length of hospital } \\
\text { stay (>48h) }\end{array}$ & 05 & 7.1 \\
\hline
\end{tabular}

Table 4: Birth weights.

\begin{tabular}{|lcc|}
\hline Birth weight $(\mathrm{g})$ & Number & Percentage \\
\hline$<2000$ & 02 & 2.8 \\
\hline $2000-3000$ & 34 & 48.5 \\
\hline $3000-4000$ & 28 & 40 \\
\hline$>4000$ & 06 & 8.5 \\
\hline
\end{tabular}

Table 5: Neonatal morbidity.

\begin{tabular}{|lll|}
\hline Morbidity & Number & Percentage \\
\hline Low apgar score at 1 min - & & \\
$0-3$ & 07 & 10 \\
$4-6$ & 12 & 17.1 \\
\hline $\begin{array}{l}\text { Low apgar score at 5 min - } \\
0-3\end{array}$ & 04 & 5.7 \\
$4-6$ & 06 & 8.5 \\
\hline NICU admission & 09 & 12.8 \\
\hline $\begin{array}{l}\text { Scalp and facial marks and } \\
\text { bruises }\end{array}$ & 07 & 10 \\
\hline Facial palsy & 02 & 2.8 \\
\hline $\begin{array}{l}\text { Subconjunctival } \\
\text { hemorrhage }\end{array}$ & 01 & 1.4 \\
\hline Still births & 03 & 4.2 \\
\hline Perinatal deaths & 02 & 2.8 \\
\hline
\end{tabular}

\section{DISCUSSION}

The rate of operative vaginal delivery in our institution during the study period was $4.2 \%$

In our study $68.5 \%$ cases requiring forceps application were primigravida, a finding similar to the reported rates in an earlier study. ${ }^{6}$ Episiotomy was given as a routine in all the patients as was also seen in another study. ${ }^{7}$ The most frequent indication for forceps application in our study was non-reassuring fetal heart rate followed by maternal exhaustion. In a study in Texas University the most common indication was fetal compromise and failure to deliver spontaneously with maximum maternal effort, which agrees with our present study. ${ }^{8}$ Our findings differed from Singh A et al, where cutting short of second stage of labor was the chief indication followed by prolonged 2 nd stage. ${ }^{9}$

Regarding maternal injuries, in our study the most common complication was extended episiotomy (14.2\%) followed by cervical and vaginal lacerations, complete perineal tear, and paraurethral tear. Johnson et al reported a high incidence of maternal third and fourth degree perineal lacerations and vaginal lacerations with the use of forceps. ${ }^{10}$ While a study in Cameroon reported only minor cervical and vaginal lacerations in cases of instrumental deliveries. ${ }^{11}$ Minor vaginal and cervical lacerations were managed by taking extra sutures during episiotomy repair. We noted 2 cases of third and fourth degree perineal tears both were primigravida and had baby weight of more than $3.5 \mathrm{~kg}$. These tears were carefully sutured under proper light in operation theatre. The patients were kept on liquid diet for one day and soft diet with stool softener for another 2 days. According to Eskander $\mathrm{O}$ et al risk factors for such tears include nulliparity, high birth weight babies and instrumental delivery for occipito-posterior position of the head, instrumental delivery for occipito anterior position of head reduces the risk of severe perineal tear. ${ }^{12}$. Complete perineal tears can also occur in unassisted vaginal deliveries in cases of large for gestational age babies, short or rigid perineum, face to pubis delivery, poor perineal support during delivery, sudden extension of the head and shoulder dystocia. In a study of long term follow up after forceps delivery it was concluded that though anal sphincter injury was associated with forceps delivery in the past, however, significant faecal and urinary incontinence was not. ${ }^{13}$ In our study there was only one case of uterine rupture. This patient had a cesarean delivery 4 years back and was undergoing trial of labour. Labour was augmented with oxytocin which might have caused hyperstimulation leading to nonreassuring fetal heart rate and need of immediate delivery using forceps. Hyperstimulation in a scarred uterus may be a possible explanation of rupture because if caused by the instrument, it generally results from a mid-cavity application of forceps, while in our study only outlet forceps were applied. In a 10 year analysis of uterine rupture Sahu L reported 125 cases of rupture in unscarred uterus out of which only 2 resulted due to instrumental deliveries. ${ }^{14}$ Women undergoing trial of vaginal birth after caesarean section already have an increased risk of intra-partum scar rupture of $0.74 \% .{ }^{15}$ Postpartum hemorrhage occurred in 4 patients who were managed with help of fluids uterotonics and blood transfusion. No significant difference was found in pph rates amongst the normal and assisted vaginal delivery groups by A Shamsa et al. ${ }^{16}$

Regarding perinatal outcome, forceps application was required in 16 babies weighing over $3.5 \mathrm{~kg}$ and 10 babies over 40 weeks of gestational age. Our findings were similar to another study where the use of instruments was 
more frequent in infants with higher birth weight and gestational age. ${ }^{17} 19$ babies had poor apgar scores of less than 6 at $1 \mathrm{~min}$ requiring immediate resuscitation. Meconium staining was present in most of these cases. Abnormal fetal heart rate pattern was the indication for forceps application in majority of them. Fetal compromise as such might have caused the poor apgar scores in these babies rather than the forceps application The decision of cesarean section in second stage for fetal distress with a deeply engaged head would have led to even worse neonatal outcome by further delaying the delivery due to time taken to shift the patient to an operation theatre and a difficult head delivery during cesarean section.

Garretta $\mathrm{K}$ et al in their study found no difference in apgar scores of new born delivered by caesarean section in $2^{\text {nd }}$ stage. ${ }^{18} 7$ babies suffered instrumental marks and bruises but majority of these were small and superficial. 2 cases of facial palsy were also noted. Observational data on instrumental deliveries have suggested that they are associated with neonatal injuries so careful practice can minimize these risks. There were 3 still births in our study and high fetal mortality could be because of late arrivals and manipulation by untrained birth attendants before coming to hospital. 9 babies required NICU admission out of which 7 were discharged within 3 days. 2 early neonatal deaths were reported.

\section{CONCLUSIONS}

Operative vaginal procedures, mainly forceps delivery, have a long history and still have a place in contemporary obstetric practice. It should be used with great caution and the delivery be supervised by trained personnel. It is a reasonable option for the obstetrician to cut down the cesarean section rates in second stage of labour but the patient must be counselled regarding the risks and benefits of alternative approaches. Skilful use of obstetric forceps with strict adherence to guidelines can minimize the maternal and neonatal morbidity.

Funding: No funding sources Conflict of interest: None declared

Ethical approval: The study was approved by the Institutional Ethics Committee

\section{REFERENCES}

1. Belfort, M. Operative vaginal delivery. ACOG Practice Bulletin, 17.2000:36-9.

2. Demissie K, Rhoads GG, Smulian JC, Balasubramanian BA, Gandhi K, Joseph KS, et al. Operative vaginal delivery and neonatal and infant adverse outcomes: population based retrospective analysis. BMJ. 2004;329:24-9.

3. Al-suhel R, Gill S, Robson S, Shadbolt B. Kjelland's forceps in the new millennium. Maternal and neonatal outcomes of attempted rotational forceps delivery. Australian and New Zealand Journal of Obstetrics and Gynaecology. 2009;49:510-4.

4. Villar J, Carroli G, Zavaleta N, Donner A, Wojdyla D, Faundes A. Maternal and neonatal individual risks and benefits associated with caesarean delivery: Multicentre prospective study. BMJ. 2007;335(7628):1025.

5. Lumbiganon P, Laopaiboon M, Gülmezoglu AM, Souza JP, Taneepanichskul S, Ruyan P, et al. Method of delivery and pre- gnancy outcomes in Asia: The WHO global survey on maternal and perinatal health 2007-08. Lancet. 2010;375(9713): 490-9.

6. Akhtar S. Comparison of maternal and infant outcome between vacuum extraction and forceps deliveries. Pakistan Armed Force Medical Journal. 2006;2(1):25-31.

7. Archanna S, Monga D. Outcome of forceps delivery versus vacuum extraction - a review of 200 cases. Singapore Med J. 1994;35(6):605-8.

8. Yeomans ER. Operative vaginal delivery. Obstet Gynecol. 2010;115:645-53.

9. Singh A, Rathore P. A comparative study of fetomaternal outcome in instrumental vaginal delivery. J Obstet Gynaecol India. 2011;61:663-6.

10. Johnson JH, Figueroa R, Garry D, Elimian A, Maulik D. Immediate maternal and neonatal effects of forceps and vacuum-assisted deliveries. Obstet Gynecol. 2004;103(3):513-8.

11. Nkwabong E, Nana PN, Mbu R, Takang W, Ekono MR, Kouam L. Indications and maternofetal outcome of instrumental deliveries atthe University Teaching Hospital of Yaounde, Cameroon. Trop Doct. 2011;41:5-7.

12. Eskander O, Shet D. Risk factors for third and fourth degree perineal tear. J Obstet gynecol. 2009;29(2):119-22.

13. Bollard RC, Gardiner A, Duthie GS, Lindow SW. Anal sphincter injury, fecal and urinary incontinence: A 34-year follow-up aft er forceps delivery. Dis Colon Rectum. 2003;46:1083-8.

14. Sahu L. A 10 year analysis of uterine rupture at a teaching institution. $\mathbf{J}$ Obstet Gynecol India. 2006;56(6):502-6.

15. Royal College of Obstetricians \& Gynaecologists. Birth after previous caesarean birth. Guideline No. 45. London: RCOG; 2007.

16. Shamsa A, Jun Bai J, Raviraj P, Gyaneshwar R. Mode of delivery and its associated maternal and neonatal outcomes. Open Journal of Obstetrics and Gynecology. 3 2013;3:307-12.

17. WuWen S, Shiliang L, Kramer SM, Marcoux S, Ohlsson A, Sauvé R, et al. Comparison of maternal and infant outcomes between vacuum extraction and forceps deliveries. Am J Epidemiol. 2001;153:103-7.

18. Garrett K, Butler A, Cohen WR. Caesarean delivery during second-stage labor: characteristics and diagnostic accuracy. J Matern Fetal Neonatal Med. 2005;17(1):49-53.

Cite this article as: Lamba A, Kaur R, Muzafar Z. An observational study to evaluate the maternal and neonatal outcome of forceps delivery in a tertiary care government hospital of a cosmopolitan city of India. Int J Reprod Contracept Obstet Gynecol 2016;5:292-5 